\title{
Characterization of dhaincha accessions based on morphological descriptors and biomass production
}

\author{
A. K. M. Golam Sarwar*, A. Islam and S. Jahan \\ Laboratory of Plant Systematics, Department of Crop Botany, Bangladesh Agricultural University, Mymensingh 2202, \\ Bangladesh. *E-mail: drsarwar@bau.edu.bd
}

\begin{abstract}
Forty five accessions of dhaincha germplasms were collected from different parts of Bangladesh and characterized on the basis of morphological descriptors and biomass production ability. Thirty eight accessions were identified as Sesbania bispinosa, four as S. cannabina and two as unidentified Sesbania spp. One accession as S. rostrata was included for comparison. Both at seedling and maturity stages, wide and significant differences were observed among the accessions of different dhaincha germplasms for their biomass production capability and other morphological descriptors. At the seedling stage, total dry mass (TDM) production varied from 10.2 to $41.6 \mathrm{~g} \mathrm{30-plants}{ }^{-1}$. At the maturity stage, plant height, total number of branches and base diameter of dhaincha germplasms varied from 347.5$474.7 \mathrm{~cm}, 10.4-23.7$, and $1.9-4.9 \mathrm{~cm}$, respectively. The highest amount $\left(4.10 \mathrm{~kg} 10-\right.$ plants $^{-1}$ ) of above-ground TDM was produced in one accession of unidentified Sesbania sp. followed by $\mathrm{S}$. rostrata and one accession of $\mathrm{S}$. cannabina $\left(3.85 \mathrm{~kg} 10-\right.$ plants $\left.^{-1}\right)$, and the lowest TDM $\left(0.9 \mathrm{~kg} 10-\right.$ plants $\left.^{-1}\right)$ was measured in two accessions of $S$. bispinosa. It may be concluded that the biomass production capability of at least two accessions of local Sesbania germplasms were higher/comparable to that of exotic S. rostrata. It will be too early to make a conclusive remark based on only a few dhaincha germplasms. A detailed study with a large number of germplasms collected from whole Bangladesh is obviously needed to reach in a precise conclusion.
\end{abstract}

Keywords: Dhaincha accessions, Characterization, Morphological descriptors, Biomass production

\section{Introduction}

Dhaincha (Sesbania spp.) belongs to the family Leguminosae (sub-family Papilionoideae), and is well known for its diversified use in Bangladesh. Three species of Sesbania viz. S. sesban (L.) Merr., S. bispinosa (Jacq.) Wight and S. cannabina (Retz.) Poir., are commonly known as dhaincha in Bangladesh (Prain, 1903; Ahmed et al., 2009). It is an ideal green manure crop as it is quick-growing, succulent, easily decomposable with low moisture requirements, and add maximum amounts of organic matter and nitrogen in the soil (Palaniappan and Siddeswaran, 2001). To lesser extents they are grown for animal feed and fodder (Shahjalal and Topps, 2000; Hossain and Becker, 2001), ground cover, providing wood, firewood and other uses in traditional agroforesty systems (Ndoye et al., 1990). It grows well even in marginal lands with little or no input. It showed a luxuriant growth in soil with a high electrical conductivity up to $10 \mathrm{mS} \mathrm{cm}^{-1}$, and some of the Sesbania spp. have been recommended for reclamation of saline and sodic soils (Chavan and Karadge, 1986). Long time (10/12 yrs) cultivation of dhaincha would combat desertification of marginal lands, e.g., char land, saline area, etc., and rehabilitate degraded lands into productive crop lands for intensive food crop agriculture (Carroll and Somerville, 2009). Dhaincha also showed its potentiality as a raw material for paper pulp (Jahan et al., 2009). Researchers, recently, have found that the leaves of dhaincha are a good source of Pinitol, an anti-diabetic compound (Misra and Siddiqui, 2004).

Dhaincha has a yield potential of up 20t DM ha ${ }^{-1}$ year $^{-1}$ under appropriate cultivation (Factsheet Sesbania sesban <http://www.tropicalforages.info/key/Forages/Media/Html/Sesbania_sesban. htm>). However, in Bangladesh condition, dhaincha produces only $1.5 \mathrm{t} \mathrm{DM} \mathrm{ha}^{-1}$ in a period on $\overline{9} 0$ days (Bokhtiar et al., 2003). Along with the native Sesbania spp., an exotic species S. rostrata is also used as green manure crop in Bangladesh. However, we do not have any dhaincha cultivar recommended by the National Seed Board for specific use yet. Selection is one of the oldest breeding procedures for genetic improvement and high yielding cultivar development (Chahal and Gosal, 2002). Agromorphological, molecular and nutritive characterization of Sesbania has been reported by several researchers (Evans and Rotar, 1987; Heering et al., 1996a, b; Hossain and Becker, 2001; Joshi-Saha and Gopalakrishna, 2007). Hitherto, there is no report on morphological characterization of dhaincha for the varietal improvement 
in Bangladesh. Biosystematics studies could be began by utilizing existing resources; however, for continued selection for plant breeding purposes, the lack of provenance-type germplasm collections from Bangladesh and even in Asia is a serious inadequacy (Evans and Rotar, 1987). Therefore, the present research has been conducted to collect and characterize the native dhaincha germplasms as a very first step to develop or recommend appropriate cultivar(s) for specific purpose(s) e.g., green manure, animal feed, pulp production, reclamation saline and/or sodic soil, etc.

\section{Materials and Methods}

A field survey was conducted at different parts of Bangladesh viz. Jhinaidaha, Chuadanga, Jasshore, Khulna, Nilphamari, Tangail, Potuakhali, in and around Bangladesh Agricultural University (BAU) campus to collect the dhaincha germplasms (Table 1).

A field experiment was conducted at the Field Laboratory of Department of Crop Botany, BAU, Mymensingh following complete randomized design (CRD) in $2 \times 3 \mathrm{~m}^{2}$ plot at the spacing of $15 \mathrm{~cm} \times 50$ $\mathrm{cm}$ (plant-plant $\times$ row-row) to study growth and compare biomass yield of collected dhaincha germplasms. Seeds were sown in the experimental field on 29 April 2014. Experimental data were collected 35 days after sowing (DAS) at the seedling, and maturity stages (80\% pod attained to characteristic colour). Thirty plants per plot were used for data collection. Base diameter was measured at $5 \mathrm{~cm}$ above the ground level. For biomass yield, seedlings were oven dried at $72 \pm 2^{\circ} \mathrm{C}$ for at least $24 \mathrm{hrs}$, mature plants were sun dried properly. Botanical identification based on morphological descriptors was done at the Plant Systematics Laboratory of the same Department following standard taxonomic procedures (Ahmed et al., 2009).

The collected data were analyzed statistically following the analysis of variance (ANOVA) technique using the Excel program in Microsoft 2007.

\section{Results and Discussion}

A total of forty five accessions of dhaincha germplasms, including one accession of the exotic introduced species Sesbania rostrata, have been collected from different parts of Bangladesh (Table 1). The S. rostrata accession was included for comparison. Based on morphological descriptors, thirty eight accessions of the collected dhaincha germplasms have been identified as S. bispinosa (syn. S. aculeata (Willd.) Pers.; Fig. 1A), four as S. cannabina (Fig. 1B), and two as unidentified Sesbania spp. (Table 1). The unidentified Sesbania accessions showed a relatively wider variation in floral and fruit morphological descriptors, which might be due to natural hybrid nature of these two accessions. The unidentified Sesbania accessions need further critical examination for proper identification.

Both at seedling and maturity stages, wide and significant differences were observed among the different dhaincha germplasms in the biomass production capability along with other morphological features (Table 2). At the seedling stage, total dry mass (TDM) production varied from 10.2 to $41.6 \mathrm{~g} 30$-plants ${ }^{-1}$ (\#009 and \#050, respectively), however, it was interesting that these dhaincha germplasms were failed to maintain their better initial growth (Table 2). On the contrary, some accessions of dhaincha germplasms performed better at later stage in spite of their poor initial growth. In an earlier experiment (Heering et al., 1996b), a large variation in dry matter yields per plant was observed in several accessions, though many accessions could not sustain their high level of production and the yields were, therefore, markedly lower at the second cut.

At the maturity stage, plant height, total number of branches and base diameter of dhaincha germplasms varied from the minimum $347.5 \mathrm{~cm}, 10.4$ and $1.9 \mathrm{~cm}$, respectively to the maximum $474.7 \mathrm{~cm}, 23.7$ and $4.9 \mathrm{~cm}$, respectively. The highest amount of above-ground TDM $\left(4.10 \mathrm{~kg} 10-\mathrm{plants}^{-1}\right)$ was produced in one accession of unidentified Sesbania sp. (\#027) followed by S. rostrata (\#105) and one accession of S. cannabina (\#025) (3.85kg 10-plants $\left.{ }^{-1}\right)$, and the lowest $\left(0.9 \mathrm{~kg} 10-\right.$ plants $\left.^{-1}\right)$ TDM in two accessions of $S$. bispinosa (Table 2). The wide variation in different morphological descriptors and biomass yield might be due to genetic make-up and/or inherent character of respective accession and/or species (Joshi-Saha 
and Gopalakrishna, 2007). Variation for above-ground DM yield between accessions of dhaincha germplasms evidencing the existence of genetic variability and the possibility of selecting higher yielding accessions of Sesbania spp. (Veasey at al., 2001). Although we did not study any correlation between parameters, high and significant correlations were found between plant dry matter yields and height and diameter, justifying the inclusion of these characters in the biomass estimation equations (Heering et al., 1996b). Significant variations were also observed in proximate analyses of fodder samples collected from different accessions of dhaincha germplasms (Ahsan et al., in preparation).

\section{Table 1. Taxonomic identity of collected accessions of dhaincha germplasms}

\begin{tabular}{|c|c|c|}
\hline Acc. No. & Collection site & Species \\
\hline 001 & Jhinaidaha, Mahespur, Mothura Seed Production Farm & S. bispinosa \\
\hline 002 & Jhinaidaha, Mahespur, Kushabhanga & S. bispinosa \\
\hline 003 & Chuadanga, Jiban-nagar, Tetulia & S. bispinosa \\
\hline 004 & Jhinaidaha, Mahespur, Kushabhanga & S. bispinosa \\
\hline 005 & Chuadanga, Jiban-nagar, Pakhila Seed Production Farm & S. bispinosa \\
\hline 006 & Jhinaidaha, Mahespur, Kushabhanga Seed Production Farm & S. bispinosa \\
\hline 007 & Jhinaidaha, Mahespur, Kushabhanga & S. bispinosa \\
\hline 008 & Jhinaidaha, Mahespur, Kushabhanga & S. bispinosa \\
\hline 009 & Jhinaidaha, Mahespur, Kushabhanga & S. bispinosa \\
\hline 010 & Jhinaidaha, Mahespur, Karincha Seed Production Farm & S. bispinosa \\
\hline 011 & Jhinaidaha, Mahespur, Kushabhanga Seed Production Farm & S. bispinosa \\
\hline 012 & Jhinaidaha, Mahespur, Karincha & S. bispinosa \\
\hline 016 & Nilphamari, Palashbari, Toronibari & S. cannabina \\
\hline 021 & Tangail, Kaliganj & S. bispinosa \\
\hline 022 & Potuakhali, Dumki, PSTU Campus & S. bispinosa \\
\hline 024 & Mymensingh, Sadar, Churkhai & S. bispinosa \\
\hline 025 & Mymensingh, Sadar, Shikarikanda & S. cannabina \\
\hline 026 & Mymensingh, Sadar, Digharkanda & S. cannabina \\
\hline 027 & Mymensingh, Sadar, Chor Gobordia & Sesbania sp. \\
\hline 028 & Mymensingh, Sadar, Agronomy Farm, Bangladesh Agricultural University & S. cannabina \\
\hline 029 & Khulna, Chuknagar, Chuknagar Bazar & S. bispinosa \\
\hline 030 & Khulna, Hogladanga, Batiahata & S. bispinosa \\
\hline 031 & Khulna, Rupsha, Alaipur & Sesbania sp. \\
\hline 032 & Khulna, Dighalia, Kumar gati & S. bispinosa \\
\hline 033 & Khulna, Dumuria, Badurgacha & S. bispinosa \\
\hline 034 & Khulna, Rupsha, Pitthavoeque & S. bispinosa \\
\hline 035 & Mymensingh, Sadar, Kalibari Chor & S. bispinosa \\
\hline 036 & Mymensingh, Sadar, Bhagnamari Chor & S. bispinosa \\
\hline 037 & Mymensingh, Sadar, Beltoly & S. bispinosa \\
\hline 038 & Jhinaidaha, Mahespur, Mathura & S. bispinosa \\
\hline 039 & Jhinaidaha, Mahespur, Gangadaspur & S. bispinosa \\
\hline 040 & Jhinaidaha, Dattanagar, Gokulnagar Seed Production Farm & S. bispinosa \\
\hline 041 & Chuadanga, Jiban-nagar, Porapara & S. bispinosa \\
\hline 042 & Chuadanga, Jiban-nagar, Pathila & S. bispinosa \\
\hline 043 & Jasshore, Keshobpur & S. bispinosa \\
\hline 044 & Jhinaidaha, Mahespur, Sankorpur & S. bispinosa \\
\hline 045 & Jhinaidaha, Mahespur, Hanifpur & S. bispinosa \\
\hline 046 & Chuadanga, Jiban-nagar, Baka & S. bispinosa \\
\hline 047 & Chuadanga, Jiban-nagar, Zadobpur & S. bispinosa \\
\hline 048 & Jhinaidaha, Mahespur, Pirgacha & S. bispinosa \\
\hline 049 & Jhinaidaha, Mahespur, Kushadanga & S. bispinosa \\
\hline 050 & Jhinaidaha, Mahespur, Karincha & S. bispinosa \\
\hline 051 & Jhinaidaha, Mahespur, Kushumpur & S. bispinosa \\
\hline 052 & Chuadanga, Jiban-nagar, Hushorkhali & S. bispinosa \\
\hline 105 & Nilphamari, Domar, Sonaroy, Koilagila & S. rostrata \\
\hline
\end{tabular}


Table 2. Morphological descriptors studied in different accessions of dhaincha germplasms

\begin{tabular}{|c|c|c|c|c|c|c|}
\hline Acc. No. & Stem Colour & 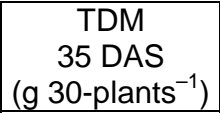 & $\begin{array}{l}\text { Plant } \\
\text { Height } \\
(\mathrm{cm})\end{array}$ & $\begin{array}{c}\text { No. of } \\
\text { Branches } \\
\left(\text { plants }^{-1}\right)\end{array}$ & $\begin{array}{c}\text { Base } \\
\text { Diameter } \\
(\mathrm{cm})\end{array}$ & $\begin{array}{c}\text { Above-ground } \\
\text { TDM } \\
\left.\text { (kg 10-plants }^{-1}\right)\end{array}$ \\
\hline 001 & Green & 30.8 & 459.1 & 14.1 & 3.1 & 2.30 \\
\hline 002 & Reddish Green & 21.5 & 394.4 & 17.0 & 3.4 & 0.90 \\
\hline 003 & Green & 15.4 & 368.8 & 16.0 & 4.2 & 0.90 \\
\hline 004 & Reddish Green & 16.5 & 363.9 & 16.2 & 3.6 & 1.00 \\
\hline 005 & Green & 28.9 & 474.7 & 20.1 & 2.7 & 1.80 \\
\hline 006 & Green & 30.2 & 444.0 & 17.4 & 2.9 & 2.10 \\
\hline 007 & Green & 12.8 & 441.9 & 12.3 & 3.1 & 1.75 \\
\hline 008 & Reddish Green & 21.6 & 407.7 & 11.1 & 2.2 & 1.70 \\
\hline 009 & Light Green & 10.2 & 365.8 & 12.8 & 3.1 & 2.00 \\
\hline 010 & Green & 20.9 & 473.1 & 17.8 & 3.1 & 2.20 \\
\hline 011 & Reddish Green & 17.7 & 456.2 & 17.6 & 2.9 & 2.45 \\
\hline 012 & Green & 24.9 & 464.0 & 18.7 & 2.9 & 2.25 \\
\hline 016 & Green & 19.8 & 347.5 & 13.0 & 1.9 & 1.10 \\
\hline 021 & Reddish Green & 19.1 & 434.9 & 14.7 & 2.4 & 2.65 \\
\hline 022 & Reddish Green & 28.2 & 394.5 & 10.4 & 3.2 & 2.75 \\
\hline 024 & Green & 30.1 & 455.4 & 13.0 & 3.1 & 2.40 \\
\hline 025 & Green & 26.1 & 416.1 & 12.1 & 2.4 & 3.85 \\
\hline 026 & Green & 31.3 & 469.2 & 13.7 & 3.0 & 2.45 \\
\hline 027 & Green & 24.2 & 389.9 & 12.7 & 2.4 & 4.10 \\
\hline 028 & Green & 33.8 & 488.2 & 20.6 & 2.9 & 3.65 \\
\hline 029 & Reddish Green & 25.1 & 424.2 & 11.8 & 2.3 & 1.00 \\
\hline 030 & Green & 29.2 & 445.4 & 16.4 & 2.5 & 1.60 \\
\hline 031 & Green & 25.6 & 433.8 & 13.7 & 2.6 & 2.15 \\
\hline 032 & Green & 30.0 & 463.5 & 14.2 & 3.1 & 1.50 \\
\hline 033 & Green & 28.2 & 394.8 & 10.6 & 2.3 & 2.35 \\
\hline 034 & Green & 26.5 & 469.9 & 14.9 & 2.8 & 1.80 \\
\hline 035 & Green & 20.4 & 419.7 & 11.7 & 2.3 & 2.30 \\
\hline 036 & Green & 17.8 & 442.7 & 16.2 & 2.7 & 2.10 \\
\hline 037 & Reddish Green & 27.6 & 424.6 & 12.5 & 2.3 & 2.25 \\
\hline 038 & Green & 19.8 & 435.0 & 13.0 & 2.5 & 2.30 \\
\hline 039 & Green & 23.6 & 418.4 & 11.6 & 2.5 & 2.15 \\
\hline 040 & Green & 14.3 & 464.2 & 14.1 & 3.0 & 1.95 \\
\hline 041 & Light Green & 19.3 & 460.6 & 17.9 & 2.6 & 1.75 \\
\hline 042 & Green & 14.6 & 424.7 & 12.3 & 2.4 & 1.85 \\
\hline 043 & Green & 23.5 & 412.9 & 11.2 & 2.4 & 1.45 \\
\hline 044 & Green & 27.2 & 417.9 & 11.6 & 2.6 & 1.75 \\
\hline 045 & Green & 33.6 & 420.5 & 14.3 & 2.6 & 2.50 \\
\hline 046 & Green & 23.9 & 452.2 & 12.5 & 3.2 & 1.10 \\
\hline 047 & Reddish Green & 40.7 & 463.0 & 23.7 & 4.9 & 1.85 \\
\hline 048 & Green & 26.9 & 450.2 & 15.3 & 2.7 & 2.22 \\
\hline 049 & Green & 25.8 & 458.9 & 14.6 & 3.3 & 1.80 \\
\hline 050 & Green & 41.6 & 460.0 & 11.5 & 3.1 & 2.45 \\
\hline 051 & Green & 29.1 & 456.0 & 15.0 & 2.9 & 2.40 \\
\hline 052 & Reddish Green & 34.1 & 457.2 & 15.4 & 2.7 & 1.75 \\
\hline 105 & Green & 13.8 & 451.4 & 18.8 & 3.0 & 3.85 \\
\hline \multirow{2}{*}{\multicolumn{2}{|c|}{$\begin{array}{c}\text { LSD } \\
\text { Level of Significant }\end{array}$}} & 5.65 & 9.50 & 4.56 & 0.55 & 0.18 \\
\hline & & 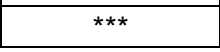 & $\star \star$ & 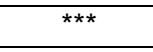 & $\star \star \star$ & $\star \star \star *$ \\
\hline
\end{tabular}

TDM: Total dry mass; DAS: Days after sowing 


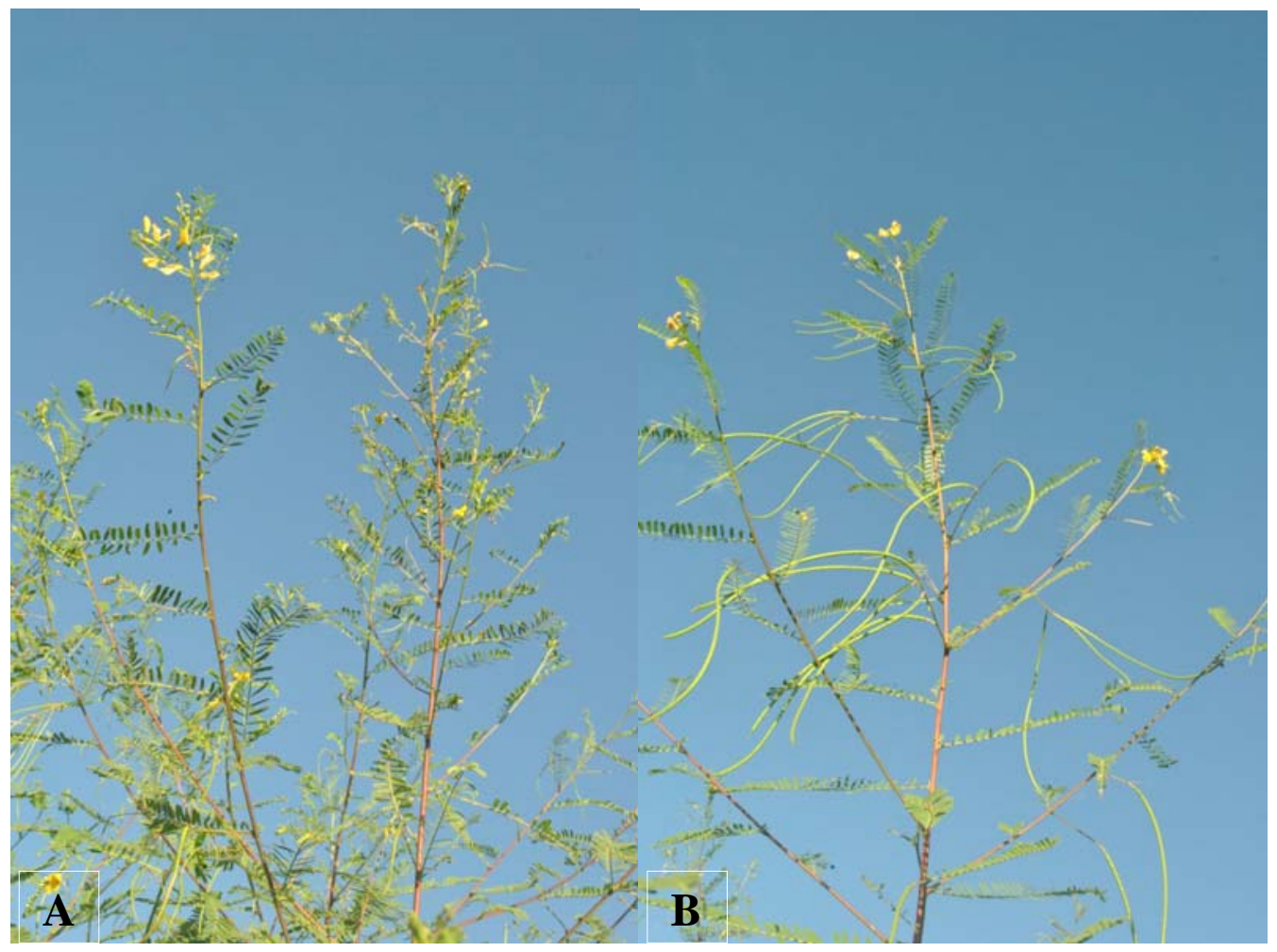

Fig. 1. Flowering shoot of Sesbania bispinosa (A) and S. cannabina (B).

It may be concluded that the biomass production capability of at least two accessions of local Sesbania germplasms (\#025 and 027) were higher/comparable to that of exotic S. rostrata (\#105). It will be too early to make a conclusive remark based on only a few dhaincha germplasms. Therefore, a detailed study with a large number of germplasm collected from whole Bangladesh is obviously needed to reach in a precise conclusion.

\section{Acknowledgement}

We acknowledge the financial support of the Ministry of Science and Technology, Government of the People's Republic of Bangladesh and the University Grants Commission of Bangladesh.

\section{References}

Ahmed, Z.U., Hassan, M.A., Begum, Z.N.T., Khondker, M., Kabir, S.M.H., Ahmad, M. and Ahmed, A.T.A. eds. 2009. Encyclopedia of Flora and Fauna of Bangladesh, Vol. 8. Angiosperms: Dicotyledons (Fabaceae-Lythraceae). Asiatic Soc. Bangladesh, Dhaka. pp. 1-474.

Bokhtiar, S.M., Gafur, M.A. and Rahman, A.B.M.M. 2003. Effects of Crotalaria and Sesbania aculeata green manures and N fertilizer on soil fertility and the productivity of sugarcane. J. Agric. Sci. 140: 305-309.

Carroll, A. and Somerville, C. 2009. Cellulosic biofuels. Ann. Rev. Plant Biol. 60: 165-182.

Chahal, G.S. and Gosal, S.S. 2002. Principles and Procedures of Plant Breeding - Biotechnological and Conventional Approach. Narosa Pub. House, New Delhi.

Chavan, P.D. and Karadge, B.A. 1986. Growth, mineral nutrition, organic constituents and rate of photosynthesis of Sesbania grandiflora L. grown under saline soil. Plants Soil 93: 395-404.

Evans, D.O. and Rotar, E.P. 1987. Sesbania in Agriculture, Westview Trop. Agric. Series; No. 8. Westview Press, Boulder (USA). 
Heering, J.H., Nokoe, S. and Mohammed, J. 1996a. The classification of a Sesbania sesban (ssp. sesban) collection. I. Morphological attributes and their taxonomic significance. Trop. Grass. 30: 206-214.

Heering, J.H., Nokoe, S. and Mohammed, J. 1996b. The classification of a Sesbania sesban (ssp. sesban) collection. II. Morphological attributes and their relation to biomass estimation. Trop. Grass. 30: 215-222.

Hossain, M.A. and Becker, K. 2001. Nutritive value and antinutritional factors in different varieties of Sesbania seeds and their morphological fractions. Food Chem. 73: 421-431.

Jahan, M.S., Rawshan, S., Banu, T., Chowdhury, D.N.A., Noori, A. and Al-Maruf. A. 2009. Effect of harvesting age on the chemical and morphological properties of dhaincha (Sesbania aculeata) and its pulpability and bleachability. BioResources 4: 471481.

Joshi-Saha, A. and Gopalakrishna, T. 2007. Agromorphological and molecular variability in the genus Sesbania. Genet. Resour. Crop Evol. 54: 1727-1736.

Misra, L.N. and Siddiqui, S.A. 2004. Dhaincha (Sesbania bispinosa) leaves: A good source of antidiabetic (+)-pinitol. Curr. Sci. 87: 10.

Ndoye, I., Tomekpe, K., Dreyfus, B., et al. 1990. Sesbania and Rhizobium symbiosis: nodulation and nitrogen fixation. In: Macklin, B. and Evans, D.O. eds. Perennial Sesbania species in agroforestry systems. Nitrogen Fixing Tree Assoc., Wamanalo. pp. 31-38.

Palaniappan, S.P. and Siddeswaran, K. 2001. Regional overview on green manure in rice-based cropping systems. In: Gowda, C.L.L., Ramakrishna, A., Rupela, O.P. and Wani, S.P. eds. Legumes in rice based cropping systems in Tropical Asia: constraints and opportunities. Int. Crop Res. Inst. Semi-Arid Trop., Patancheru (India). pp. 126-135.

Prain, D. 1903. Bengal Plants, Vols. I \& II. Indian Rep., 1981, B. Singh \& M.P. Singh, India.

Shahjalal, M. and Topps, J.H. 2000. Feeding Sesbania leaves as a sole feed on growth and nutrient utilization in goats. Asian-Aus. J. Anim. Sci. 13: 487-489.

Veasey, E.A., Schammass, E.A., Vencovsky, R., Martins, P.S. and Bandel, G. 2001. Germplasm characterization of Sesbania accessions based on multivariate analyses. Genet. Resour. Crop Evol. 48: 79-90. 